the influence of this deformation on the measurements by making alternate experiments with pure water (for the reference scale, for details see Pedersen, loc. cit.) and the salt solution. In this manner we are able to relate values for a certain run to the run immediately before and immediately after it (each run took 6-8 hours).

By using this procedure there could be measured the change in concentration in the cell for such low molecular weight substances as $\mathrm{NaCl}, \mathrm{LiCl}$ and the simplest amino acid (glycocoll). The molecular weights found were: for $\mathrm{NaCl} 57 \cdot 4(58 \cdot 454)$, for $\mathrm{LiCl} 37 \cdot 8$ $(42 \cdot 397)$ and for glycocoll $68 \cdot 1(75 \cdot 05)$. The values in parenthesis give the true molecular weights. This result means that it is actually possible by means of the ultra-centrifuge to determine the molecular weight of all substances (soluble to a certain extent in water) from $\mathrm{LiCl}$ up to the huge hæmocyanine molecules (molecular weight 6,000,000).

The experimental difficulties connected with the gradual deformation of the cell we hope to be able to overcome by introducing certain alterations in its construction.

The calculations of these experiments were carried out in a somewhat different way from that used before ${ }^{1}$, introducing the refractive index increment of the substance. Assuming that the same total amount of substance is present in solution in the cell when the equilibrium is established as at the start, it is possible by means of an integration method to determine the concentration of the substance at any point of the cell, and after this the molecular weight may be calculated either in the usual way or by introducing the value found for $d c / d x$ in the differential formula for the molecular weight.

Details will be published elsewhere.

KaI O. Pedersen.

Laboratory of Physical Chemistry,

$$
\text { University of Uppsala, }
$$

Uppsala, Sweden.

Dec. 22.

${ }^{1}$ Kai O. Pedersen, Z. phys. Chem., A, 170, 41; 1934

2 The Svedberg, G. Boestad and I.-B. Eriksson-Quensel, NATURE, 134,$98 ; 1934$.

'Ole Lamm, Z. phys. Chem., A, 138, 313 ; 1928. 143, 177; 1929.

\section{Use of the Centrifuge in Determining the Density of Small Crystals}

Iv a previous letter ${ }^{1}$ we described a method of determining the density of small crystals of a substance with the centrifuge for the purpose of determining its molecular weight. It has since been brought to our notice that essentially the same method has been used by S. B. Hendricks ${ }^{2}$ though with a different object. We should, therefore, like to correct the impression that we claim any novelty for this method of density-determination, while still wishing to point out its usefulness as a method of determining molecular weights to a high degree of accuracy.

Crystallography Laboratory, Cambridge.

\section{J. D. Bernal.}

Department of Mineralogy, Oxford.

'NATURE, 134, 809 ; 1934.

2J. Opt. Soc. Amer., 23, 299 ; 1933.

\section{Mechanism of Respiration}

THE respiration of the minced breast muscle of the pigeon has been studied by means of specific poisons (malonic, maleic and arsenious acid). Experiments show that in the main process of respiration, no substances other than succinic acid and its first oxidation product, fumaric acid and the hydrate of the latter, malic acid, are oxidised directly by the Warburg-Keilin 'Atmungsferment-Cytochrom' system. Both succinic and malic acids are activated by the corresponding specific dehydrogenase. Only these two dehydrogenases seem to be connected immediately with the Warburg-Keilin system. Succinic acid is oxidised by them to fumaric, malic to hydroxyfumaric acid. Both oxidations are reversible.

Foodstuffs are oxidised by dismutating them with oxidation products of succinic acid, which products thereby become re-reduced and act thus as catalytic hydrogen carriers. The 'oxidation system' is an enzyme complex acting specifically on succinic acid and its oxidation products. Fermentation is an intramolecular dismutation. Oxidation is dismutation with oxidised succinic acid.

This research has been sponsored by the Josiah Macy, Jr., Foundation, New York.

Institute of Medical Chemistry,

A. Szent-Györcyr.

Szeged.

Jan. 26.

\section{Cosmical Chemistry}

MaNy will read with interest and admiration Prof. H. N. Russell's fascinating and masterly address published as a supplement to NATURE of February 9 ; it is all that an address should be on such an occasion. Having watched the story of ultramundane chemistry unfold from all but its Bunsen and Kirchoff-Stokes beginning, especially during the turbulent Lockyer period, I perhaps can appreciate both its beauty and the greatness of our advance in knowledge more than most, so may be allowed to tender to Prof. Russell the thanks that so many, I am sure, will wish to express.

What would the founder and first editor of NATURE have said to the use made of the spectroscope since he turned his instrument to the sun and discovered helium, the only element discovered in the sun, perhaps some day, when we draw pictures of atomic structure as we now do of molecular, to be recognised as the fundamental element as benzene is the fundamental carbohydride? The wave of enthusiasm then excited has rolled on with ever increasing amplitude and certainty of direction.

The cosmos stands revealed before us, in wondrous simplicity too. Even organic chemistry is lifted up to the stars and shown to have the simplest possible beginning there in methane, together with ammonia. Some planets, it seems, may be worlds of Franklin chemistry; with ammonia as snow.

We are in face of a transcendent geology but whilst readers of NATURE may geologise on Mars and recognise ferric red on its surface rocks, few of our schools pay the least attention to mundane geology. Dust has no ethics in most eyes: our women wear it but without understanding. Love of colour is a barbaric trait-understanding is not. Are the masses ever to remain barbarians? What is to be the use of leisure in the future ? At least, we should seek to civilise our politicians and all who strive to 